\title{
PENGGUNAAN DEIKSIS PADA NOVEL MY LECTURER MY HUSBAND KARYA GITLICIOUS
}

\author{
Asih Rosnaningsih \\ Universitas Muhammadiyah Tangerang \\ asihrosna@gmail.com
}

\begin{abstract}
ABSTRAK
Bahasa tulis merupakan suatu bentuk komunikasi yang digunakan dengan menggunakan media tertulis yang sangat luas cakupannya. Suatu struktur yang lengkap dalam penulisan, kosakata dan juga dalam usaha memahaminya sangat diperlukan yang terdapat bentuk komunikasi dalam novel $M y$ Lecturer My Husband. Pengarang berusaha menciptakan komunikasi dengan menggunakan kata-kata atau ungkapan yang berfungsi sebagai penunjukan atau diberi nama deiksis. Penelitian ini bertujuan untuk menganalisis penggunaan deiksis dalam Novel My Lecturer My Husband. Penelitian ini merupakan penelitian kualitatif menggunakan metode analisis deskriptif. Data dalam penelitian ini yaitu teks novel novel Novel My Lecturer My Husband yang mengandung deiksis Sumber data penelitian ini adalah novel Novel My Lecturer My Husband yang dibagi menjadi tiga jenis deiksis yaitu: (1) deiksis persona, (2) deiksis spatial, dan (3) deiksis temporal. Teknik pengumpulan data yaitu dengan studi dokumen. Teknik analisis data menggunakan tiga langkah yaitu pengumpulan data oleh Miles and Huberman yaitu: data reduksi, data display dan menarik kesimpulan. Hasil dari analisis data dalam penelitian ini ditemukan bahwa: (1) deiksis persona orang pertama sebanyak 5 kata, persona orang kedua sebanyak 3 kata, dan persona orang ketiga sebanyak 6 kata, (2) deiksis spatial proximal sebanyak 2 kata, dan deiksis distal terms sebanyak 2 kata, (3) deiksis temporal masa lalu sebanyak 6 kata, sekarang sebanyak 4 kata, dan masa depan sebanyak 7 kata. Berdasarkan dari hasil penelitian yang telah ditemukan, maka sangat penting sekali untuk mempelajari deiksis agar suatu pesan yang ingin disampaikan pengaran dapat dipahami dengan baik oleh pembacanya agar terjadi komunikasi yang efektif dan kata-kata yang disampaikan dapat memiliki makna yang jelas
\end{abstract}

Kata Kunci: deiksis, novel, penelitian kualitatif

\section{A. PENDAHULUAN}

Deiksis merupakan salah satu pembahasan yang paling sering dikaji dari ilmu pragmatik. Menurut Yule (2014:4) pragmatik merupakan setudi tentang makna yang disampaikan oleh seorang penutur atau mitra tutur dan ditafsirkan oleh pendengar atau pembaca. Ilmu pragmatik yang mengamati lebih dalam mengenai fenoma-fenoma penggunaan deiksis dalam kehidupan nyata atau dalam karya sastra seperti novel, cerpen, teks drama dan lainnya. Deiksis sebuah kata dipelajari identitas yang referensinya selalu berubah sesuai dengan konteks penggunaannya. Suhartono (2017:15-16) mendefinisikan deiksis sebagai penunjukan atau pengacuan yang selalu berubah-ubah, berpindah, atau berganti tergantung dari perspektif penutur dalam suatu wacana dimana komunikasi itu dilakukan. Rahardi (2019: 216) menambahkan bahwa deiksis menjadi salah satu dari fenomena pragmatik yang membicarakan kaidah-kaidah penunjukan, baik yang menunjukan 


\section{Lingua Rima: Jurnal Pendidikan Bahasa dan Sastra Indonesia \\ Vol. 10 No. 2 Juli 2021 \\ http://jurnal.umt.ac.id/index.php/lgrm}

waktu, tempat, orang, masyarakat yang penentunya adalah konteks. Deiksis dapat menimbulkan keteraturan dan keefektifan dalam berbahasa sehingga makna yang ingin disampaikan menjadi jelas dan tidak rancu serta tidak menyebabkan misinterpretasi pada pembacanya.

Menurut Suhartono (2017:15-16) menjelaskan ada tiga jenis deiksis yang umumnya ditemui yaitu: (1) deiksis orang (person deixis), (2) deiksis spasial menunjukkan idensikal kedekatan (proximal terms) atau jarak (distal terms), dan (3) deiksis temporal yang berhubungan dengan waktu. Renkema (1993: 77) menjelaskan bahwa deiksis persona mengacu pada orang yang ingin dirujuk oleh si pembicara yang berarti deiksis persona adalah mengacu pada kata ganti orang. Tuturan tersebut diarahkan dari orang pertama (saya) kepada pendengar, orang kedua (Anda) dan orang yang dibicarakan pembicara adalah orang ketiga (dia, dia, itu). Giergji (2015: 137) menjelaskan bahwa deiksis spasial menggambarkan tempat dan menggambarkan di mana lokasi relatif orang dan objek ditunjukkan.

Penggunaan deiksis ini juga dapat secara mudah diidentifikasi baik dalam sumber wacana lisan dan tulisan. Salah satu sumber tulisan yang terdapat didalamnya deiksis adalah dalam bentuk novel. Novel adalah sebuah cerita berbentuk prosa fiktif dengan panjang atau rentang tertentu dimana didalamnya melukiskan karakter, gerak maupun adegan nyata yang menceritakan suatu alur atau keadaan yang agak kacau atau kusut. Novel juga memiliki ciriciri adanya tokoh, menceritakan lebih dari satu impresi, menyajikan lebih dari satu efek dan menyajikan lebih dari satu emosi. (Tarigan, 1991: 164-165)

Salah satu novel yang sangat menarik untuk dikaji penggunaan deiksisnya adalah Novel My Lecturer My Husband yang diterbitkan pada tahun 2017 dengan pengarang Gitlicious. Novel ini menjadi salah satu novel dengan predikat Best Seller dan sudah dibaca oleh 4 juta pembaca di aplikasi Wattpad. Novel ini mengisahkan tentang seorang mahasiswi bernama Inggira Almira Arundati yang menjalani kehidupan barunya Bersama suaminya sekaligus dosennya di kampus yaitu Sadewa Bentara Arya yang terkenal kaku dan killer. Mereka menjalani kehidupan pernikahan di belakang sahabat-sahabatnya yaitu genk OSM dimana dalam novel tersebut disajikan alur demi alur erita yang sangat menarik. Berdasarkan dari asumsi tersebut makan peneliti bertujuan untuk menganalisis penggunaan deiksis dalam novel "My Husband My Lecturer" karena peneliti menganggap novel ini mengandung fenomena deiksis dalam peristiwa tindak tutur yang dianggap layak dijadikan sebagai objek kajian penelitian. 
Lingua Rima: Jurnal Pendidikan Bahasa dan Sastra Indonesia

Vol. 10 No. 2 Juli 2021

http://jurnal.umt.ac.id/index.php/lgrm

Penelitian yang dilakukan oleh Nursalim dan Alam (2019) yang berjudul Pemakaian Deiksis Persona dalam Cerpen di Harian Republika menghasilkan n beberapa bentuk deiksis persona dalam cerpen tersebut seperti pronomina persona pertama tunggal dan jamak, pronomina persona kedua tunggal dan jamak, dan pronomina persona ketiga tunggal dan jamak. Kemudian, menemukan fungsi deiksis persona dalam cerpen tersebut seperti merujuk pada orang yang berbicara, merujuk pada orang yang diajak bicara, dan merujuk pada orang yang dibicarakan dalam cerita. Sedangkan penelitian oleh Abidin, Sariban, dan Selirowangi (2019) berjudul Deiksis dalam Novel Merindu Baginda Nabi Karya Habiburrahman El Shirazy menghasilkan 1) penggunaan deiksis persona berupa saya, kamu dan mereka, 2) terdapat deiksis tempat yaitu sana, sini dan ini, 3) deiksis waktu yaitu nanti, dulu dan sekarang, 4) deiksis wacana yaitu berupa klausa mereka menang baca, sebaiknya kita tidak menggunjing dia, 5) deiksis kata ganti, dia menjadi beliau.

\section{B. METODE PENELITIAN}

Penelitian ini merupakan penelitian kualitatif menggunakan metode analisis deskriptif. Data dalam penelitian ini, teks novel My Lecturer My Husband yang mengandung deiksis. Sedangkan sumber data dalam peneitian ini berupa novel My Lecturer My Husband. Peneliti ingin menganalisis penggunaan deiksis dalam Novel My Lecturer My Husband. Teknik pengumpulan data menggunakan studi dokumen dengan menganalisis tiga jenis deiksis yang di analisis yaitu: (1) deiksis persona, (2) deiksis spatial, dan (3) deiksis temporal. Teknik analisis data menggunakan tiga langkah yaitu pengumpulan data oleh Miles and Huberman yaitu: data reduksi, data display dan menarik kesimpulan.

\section{HASIL DAN PEMBAHASAN}

\section{Analisis Deiksis Persona}

Berikut adalah hasil rekapitulasi dari temuan deiksis persona ditampilkan dalam table dibawah ini:

Tabel 4.1 Temuan Deiksis Persona dalam Novel My Lecturer My Husband

\begin{tabular}{clll}
\hline \multirow{2}{*}{ Nomor } & \multicolumn{3}{c}{ Bentuk Deiksis Persona } \\
\cline { 2 - 4 } & Persona I & Persona II & Persona III \\
\hline 1. & Gue & Kalian & Dia \\
\hline 2. & Saya & Kamu & Mereka \\
\hline 3. & Kami & Lo & - \\
\hline 4. & Aku & - & -
\end{tabular}


Lingua Rima: Jurnal Pendidikan Bahasa dan Sastra Indonesia

Vol. 10 No. 2 Juli 2021

http://jurnal.umt.ac.id/index.php/lgrm

5. Kita

Deiksis Persona dapat dikategorikan menjadi tiga jenis sesuai dengan penutur atau kata ganti orang (pronomina). Kata ganti orang pertama (Persona I) sebagai contoh: kata $a k u$, saya untuk orang pertama tunggal, dan kata kami, kita untuk orang pertama jamak. Kata ganti orang kedua (Persona II) sebagai contoh: kamu, anda, engkau untuk orang kedua tunggal, dan kalian, anda semua untuk orang kedua jamak. Terakhir, kata ganti orang ketiga (Persona III) sebagai contoh: dia, ia, beliau untuk orang ketiga tunggal, dan mereka untuk orang ketiga jamak. Berikut deiksis persona yang ditemukan dalam tuturan novel My Lecturer My Husband:

\section{a. Contoh Deiksis Persona I}

"Tapi gue masih heran, lo sama Rara kan ngumpulin tugas bareng terus ya? Dia dapet A. Cuma lo sendiri yang melenceng jauh dapet C. " (hal.1)

Kata gue disini mengacu pada diri si penutur sendiri bernama Joana Haura, yang sedang berbicara kepada kedua temannya Inggit dan Rara. Kata gue diatas memiliki kategori orang pertama tunggal.

"Ya udah, nanti saya pikirin. Kamu WA saya aja nanti" (1a, hal.4)

“Tapi saya gak punya nomor Bapak,” Kata gue gak enak. (1b, hal.4)

Pada bentuk tuturan tersebut terdapat dua kata saya. Pada kalimat 1a, kata saya disini mengacu langsung kepada penutur yaitu Pak Arya (dosen) yang sedang melakukan pembicaraan dengan Inggit. Sebaliknya pada kalimat $1 b$, kata saya mengacu pada Inggit (mahasiswa) yang menegaskan bahwa ia tidak memiliki nomor WA dari Pak Arya. Kedua kata saya tersebut berkategori orang pertama tunggal.

Kami kenal karena pesta ulang tahun Juna saat semester dua, kami jadian di semester tiga, dan hubungan kami sudah jalan satu setengah tahun. (hal.6)

Kata kami dalam potongan cerita diatas mengacu pada pembiacaraan sebelumnya dimana kata kami disini mengacu kepada Inggit dan Kara yaitu pacarnya yang merupakan mahasiswa fakultas kedokteran yang berkuliah di kampus yang sama. Kata kami diatas merupakan contoh dari deiksis orang pertama jamak.

“Kalau udah selesai makannya, ayo kita lanjutin tugas kamu!'(hal.11)

Kata kita pada dialog diatas mengacu kepada Inggit dan Kara yang sedang menyelesaikan tugas disebuah rumah makan cepat saji (McDonalds) yang terletak dekat dengan apartemen Inggit. Mereka sedang berusaha menyelesaikan tugas remedial mata kuliah 
Lingua Rima: Jurnal Pendidikan Bahasa dan Sastra Indonesia

Vol. 10 No. 2 Juli 2021

http://jurnal.umt.ac.id/index.php/lgrm

yang diberikan oleh Pak Arya. Kata kita diatas merupakan contoh dari pronomina orang pertama jamak.

b. Contoh Deiksis Persona II:

"Emang kamu sudah resmi ganti semester? Libur saja belum," kata dia datar, tapi nyelekit. (hal.3)

Kata $\mathbf{k a m u}$ dalam potongan kalimat diatas mengacu kepada orang yang sedang diajak berbicara oleh Pak Arya, yaitu Inggit. Kamu disini adalah merupakan pronomina untuk kata ganti orang kedua tunggal.

"Hei, Kalian lagi ngapain?!" Tanya Yuda yang langsung merangkul istrinya Iim. (hal.2)

Kata kalian dalam potongan dialog diatas mengacu pada orang yang diajak berbicara oleh si penutur utama (Yuda) yaitu teman-temannya yang bernama Inggit, Rara, Joana dan Iim. Kata kalian diatas merupakan contoh dari deiksis orang kedua jamak.

\section{c. Contoh Deiksis Persona III:}

"Dia parah banget akhir-akhir ini, lebih-lebih dari PMS" kata Rara memperingati Juna. Ya emosi gue emang gak terkontrol karena dosen sialan itu.(hal.16)

Kata dia diatas mengacu pada orang yang dibicarakan oleh penutur dan lawan bicaranya. Disini Juna (penutur) dan Rara (lawan bicara) sedang membicarakan tentang dia (yaitu Inggit) yang emosinya belakangan ini meledak-ledak. Kata dia pada percakapan diatas merupakan pronomina orang ketiga tunggal.

“Oke, kalau gitu saya yang akan keluar dan ngomong sama mereka," kata Pak Arya sambil beranjak pergi. (hal. 102)

Kata mereka pada pembicaraan diatas mengacu pada orang yang dijadikan objek pembicaraan oleh penutur dan lawan bicaranya. Pada saat itu Pak Arya sedang berbicara kepada Inggit tentang teman-temannya. Jadi kata mereka itu mengacu kepada teman-teman Inggit yang bernama Joana, Juna, Altab, Hanif, Calvin dan Rara. Kata mereka pada percakapan diatas merupakan pronomina orang ketiga jamak.

\section{Analisis Deiksis Spatial}

Berikut adalah hasil rekapitulasi dari temuan deiksis spatial ditampilkan dalam table dibawah ini:

Tabel 4.2 Temuan Deiksis Spatial dalam Novel My Lecturer My Husband

\begin{tabular}{llc}
\hline Nomor & \multicolumn{2}{c}{ Bentuk Deiksis Spatial } \\
\cline { 2 - 3 } & Proximal & Distal
\end{tabular}


Lingua Rima: Jurnal Pendidikan Bahasa dan Sastra Indonesia

Vol. 10 No. 2 Juli 2021

http://jurnal.umt.ac.id/index.php/lgrm

\begin{tabular}{lll}
\hline 1 & Ke sini & Ke sana \\
\hline 2 & Di sini & Di sana \\
\hline
\end{tabular}

\section{a. Contoh Deiksis Proximal Terms}

"Please, Jo, cowok lo mabok juga emang lo mau nginep di apartemennya? Mending di sini aja sama kita. Temenin gue yang jomblo sendirian male mini," mohon gue ke Joana. (hal.68)

Ekspresi kata di sini bermakna bahwa lokasi yang diutarakan dalam pembicaraan diatas mengacu pada posisi terdekat dimana Inggit dan Joana sedang berbicara. Kata di sini mengacu kepada Sports Bar dimana mereka merayakan pesta ulang tahun Altan. Kata di sini pada percakapan diatas merupakan bagian dari deiksis proximal terms.

\section{b. Contoh Deiksis Distal Terms}

Kita akhirnya kembali lagi ke kantin, di sana masih ada Calvin sama Rara, dan Joana uga Juna. Iim dan Yuda sudah menghilang entah kemana. (hal.6)

Pada unit percakapan diantara Inggit dan Kara terdapat jarak yang cukup jauh diantara satu titik lokasi dengan titik lainnya. Kata di sana mengacu pada jarak diantara kelas tempat kuliah menuju ke kantin kampus.

\section{Analisis Deiksis Temporal}

Berikut adalah hasil rekapitulasi dari temuan deiksis temporal ditampilkan dalam table dibawah ini:

Tabel 4.3 Temuan Deiksis Temporal dalam Novel My Lecturer My Husband

\begin{tabular}{clll}
\hline \multirow{2}{*}{ Nomor } & \multicolumn{3}{c}{ Bentuk Deiksis Temporal } \\
\cline { 2 - 4 } & Masa Lalu & Sekarang & Masa Depan \\
\hline 1 & Kemarin & Hari ini & Besok pagi \\
\hline 2 & Lalu & Sekarang & Besok \\
\hline 3 & Dulu & Akhir-akhir ini & Semester depan \\
\hline 4 & Tadi & Saat ini & Dua minggu lagi \\
\hline 5 & Semester kemarin & - & Nanti malam \\
\hline 6 & Malam sebelumnya & - & Nanti sore \\
\hline 7 & - & - & Nanti \\
\hline
\end{tabular}

\section{a. Contoh Deiksis Temporal Masa Lalu}

"Permisi, Pak, saya mahasiswa yang mengikuti mata kuliah Bapak semester kemarin." (hal.3)

Kata semester kemarin dalam percakapan di atas mengacu kepada bentuk masa lampau. Semester dimana Inggit mengikuti mata kuliah dengan Pak Arya sebagai dosen pengampunya. Semester kemarin merupakan temporal untuk kata ganti waktu masa lalu. 
Lingua Rima: Jurnal Pendidikan Bahasa dan Sastra Indonesia

Vol. 10 No. 2 Juli 2021

http://jurnal.umt.ac.id/index.php/lgrm

Cuma satu yang kurang kalau dia udah sibuk sama tugas dan game-nya, dia gak pernah inget buat ngasih kabar. Hal itu bahkan sempat jadi salah satu penyebab kami putus semester lalu. (hal.6)

Kata semester lalu dalam penggalan novel di atas mengacu kepada bentuk masa lampau. Kata semester lalu mengacu kepada rentang waktu dimana Inggit mengalami putus hubungan dengan pacarnya Kara. Semester lalu merupakan deiksis temporal untuk kata ganti waktu masa lalu.

Gue selesai siding dengan perasaan yang luar biasa Bahagia dan juga lega. Meski sempat mendapatkan beberapa pertanyaan, gue lancar menjawabnya. Semua berkat suami gue yang ngajarin gue di malam sebelumnya. (hal.121)

Kata malam sebelumnya dalam penggalan cerita di atas mengacu kepada bentuk masa lampau. Kata malam sebelumnya merupakan waktu dimana Inggit diajarkan oleh suaminya yaitu Pak Arya satu malam sebelum hari sidang skripsinya. Malam sebelumnya merupakan deiksis temporal untuk kata ganti masa lalu.

"Arya nelepon tadi, dia bingung karena kamu demam, terus dia nanya kalau kamu sakit biasanya suka makan apa. Mamah jawab aja biasanya kamu makan bubur sama minum susu beruang, dan gak lama kamu sembuh." (hal.139)

Analisis: Kata tadi pada potongan percakapan di atas mengacu kepada bentuk masa lampau. Kata tadi merupakan waktu dimana suami Inggit yaitu Pak Arya menelpon orang tuanya sesaat sebelum dia berbicara kepada Inggit. Tadi merupakan deiksis temporal untuk kata ganti masa lalu.

\section{b. Contoh Deiksis Temporal Sekarang}

"Shhh... Udah jangan bahas itu lagi, aku gak mau hari ini kita berantem," bujuk Kara sambil mengacak rambut gue dengan lembut. (h.11)

Kata hari ini dalam penggalan novel diatas mengacu pada bentuk waktu sekarang. Kata hari ini merupakan hari Kara bertemu dengan Inggit di sebuah restaurant untuk mengerjakan tugas tambahan yang diberikan oleh Pak Arya. Hari ini merupakan deiksis temporal untuk kata ganti sekarang.

Seketika gue mengingat omongan gue kemarin, dan meringis miris kenapa omongan gue akhir-akhir ini malah menjadi nyata. (hal.23)

Kata akhir-akhir ini dalam kalimat di atas mengacu pada bentuk waktu sekarang. Kata akhir-akhir ini merupakan saat dimana si pembicara yaitu Inggit merasa bahwa apa yang ia ucapkan menjadi kenyataan di jangka waktu tersebut. Akhir-akhir ini merupakan deiksis temporal untuk kata ganti sekarang. 
Lingua Rima: Jurnal Pendidikan Bahasa dan Sastra Indonesia

Vol. 10 No. 2 Juli 2021

http://jurnal.umt.ac.id/index.php/lgrm

Gue memutar otak untuk mencari celah lain saat ini. (hal.23)

Kata saat ini dalam kutipan novel di atas mengacu pada bentuk waktu sekarang. Kata saat ini merupakan saat dimana Inggit ingin mencari solusi supaya tidak jadi dijodohkan dengan calon suaminya Pak Arya. Saat ini merupakan deiksis temporal untuk kata ganti sekarang.

"Orang tua kamu juga dijodohin kan? Sama kaya orang tua saya, seharusnya kamu gak sehisteris ini sekarang." (hal.25)

Kata sekarang dalam penggalan cerita di atas mengacu pada bentuk waktu saat ini ketika pembicara menuturkan ujarannya. Kata sekarang merupakan penegasan dari Pak Arya yang sedang berbicara dengan Inggit tentang perjodohan yang sedang berlangsung. Sekarang merupakan deiksis temporal untuk kata ganti waktu yang sedang berlangsung (saat ini).

\section{c. Contoh Deiksis Temporal Masa Depan}

"Kamu yang kemarin kan? Bikin aja makalah tentang mata kuliah saya. Tema bebas, minimal tiga puluh halaman. Semua harus rapih dengan format spasi dan huruf seperti skripsi. Kalau gak tau formatnya, tanya senior kamu yang lagi skripsi, dan besok pagi udah ada di meja saya," kata dia tanpa jeda. (hal.8)

Kata besok pagi dalam penggalan cerita di atas mengacu pada bentuk waktu yang akan datang. Dalam percakapan di atas Pak Arya menjelaskan bahwa Inggit harus menyerahkan tugas makalah untuk persyaratan perbaikan nilainya pada keesokan hari. Besok pagi merupakan deiksis temporal untuk kata ganti waktu esok hari dengan waktu yang spesifik yaitu pada saat matahari baru saja terbit.

Jangankan untuk beli kue atau cupcake, untuk besok pergi ke kampus aja gue pasti minta jemput salah satu teman gue atau Kara sebagai sarana pengiritan. (hal.13)

Kata besok dalam penggalan cerita di atas mengacu pada bentuk waktu yang akan datang. Dalam kutipan novel di atas Inggit menjelaskan bahwa untuk pergi ke kampus esok hari ia harus meminta bantuan kepada salah satu temannya atau Kara yaitu pacarnya. Besok merupakan deiksis temporal untuk kata ganti waktu perkuliahan yang belum spesifik.

Dan gue memekik heboh saat melihat nama Sadewa Bentara Arya ada di daftar dua mata kuliah yang harus gue tempuh di semester depan.(hal.17)

Kata semester depan dalam penggalan cerita di atas mengacu pada bentuk waktu yang akan datang. Pada kutipan di atas terlihat Inggit sangat terkejut karena ada dua mata kuliah yang akan di ampu oleh Pak Arya dimana perkuliahan akan di mulai semester yang akan dating. Semester depan merupakan deiksis temporal untuk kata ganti waktu spesifik yaitu enam bulan kemudian. 
Lingua Rima: Jurnal Pendidikan Bahasa dan Sastra Indonesia

Vol. 10 No. 2 Juli 2021

http://jurnal.umt.ac.id/index.php/lgrm

Mau gak mau, siap gak siap, dua minggu lagi saya akan tetap ke sini untuk nikahin kamu agar gak malu-maluin keluarga saya. Kalau kamu mau malu-maluin keluarga kamu, itu terserah kamu. (hal.32)

Kata dua minggu lagi dalam penggalan cerita di atas mengacu pada bentuk waktu yang akan datang. Pak Arya menjelaskan bahwa dia akan tetap berencana menikah dengan Inggit dalam rentang waktu dua minggu yang akan datang. Dua minggu lagi merupakan deiksis temporal untuk kata ganti waktu yang spesifik dua minggu kemudian.

"Jadi saya beneran gak boleh nonton?" Tanya gue. "Boleh, nanti malam sama saya." Kalau gitu mendingan gak usah nonton. (hal.103)

Kata nanti malam dalam penggalan cerita di atas mengacu pada bentuk waktu yang akan datang. Dikisahkan bahwa Inggit ingin menonton dan meminta izin suaminya yaitu Pak Arya namun kepergian mereka belum terlaksana dan akan berangkat pada saat malam hari. Nanti malam merupakan deiksis temporal untuk kata ganti waktu yang spesifik yaitu saat matahari sudah tenggelam.

\section{KESIMPULAN}

Pengetahuan terhadap deiksis tentu saja sangat bermanfaat bagi pembaca novel karena pada deiksis suatu kata dapat diketahui berdasarkan konteks kejadian atau situasi tertentu. Aturan dalam deiksis merupakan suatu kaidah untuk mengetahui keterkaitan makna dari sebuah kata terhadap siapa, dimana, kapan, dan dalam kontek apa kata tersebut diujarkan. Penunjukan yang ditemukan berupa kata-kata yang mengacu pada orang (deiksis persona), tempat (spatial), dan waktu (temporal) dimana kata-kata tersebut diujarkan. Dengan mempelajari penggunaan deiksis pada novel My Lecturer My Husband, para pembaca dapat memahami dan membedakan setiap makna kata dan penggunaan makna tersebut sesuai dengan konteksnya. Dengan demikian, pembaca dapat menyimpulkan atau membuat interpretasi yang baik dari sebuah teks tertulis sebagai mana yang dimaksud oleh pengarangnya.

\section{E. DAFTAR PUSTAKA}

Abidin, Jauharul, Sariban, dan Selirowangi, Nisaul Barokati.2019. Deiksis dalam Novel Merindu Baginda Nabi Karya Habiburrahman El Shirazy. Jurnal Pentas. Vol 5 No 1 PP 74-80 
Lingua Rima: Jurnal Pendidikan Bahasa dan Sastra Indonesia

Vol. 10 No. 2 Juli 2021

http://jurnal.umt.ac.id/index.php/lgrm

Giergji, S. 2015. A pragmatic Analysis of the Uses of Types of Deixis in Poetry and Novels of Ismail Kadare. Academicus International Scientific Journal. Diakses 10 Juni 2021 dari www.academicus .edu.al.

Nursalim, Misbah Priagung dan Alam, Syahrobi Nur. 2019. Pemakaian Deiksis Persona dalam Cerpen di Harian Republika. Jurnal Deiksis. Vol 11 No 2 PP 121-129

Rahardi, K. 2019. Pragmatik: Konteks Intralinguistik dan Konteks Ekstralinguistik. Yogyakarta: Penerbit Amara Books.

Renkema, J. 1993. Discourse Studies: An Introductory Textbook. Amsterdam: John Benjamin Publishing Company.

Suhartono. 2020. Pragmatik Konteks Indonesia. Gresik: Penerbit Graniti.

Tarigan, H.G. 1991. Prinsip-Prinsip Dasar Sastra. Bandung: Angkasa Bandung.

Yule, G. 2014. Pragmatik. Yogyakarta: Pustaka Pelajar. 